\title{
LOS PRINCIPIOS DEL DERECHO COMO FUENTE EL DERECHO
}

\author{
Mario Romero Antola. ${ }^{1}$
}

\begin{abstract}
"Uno de los descubrimientos más importantes de la humanidad, ha significado la identificación y construcción, por una parte, de los principios generales del derecho, y por la otra, de un lenguaje normativo que establece derechos y obligaciones de los seres humanos para el efecto de vivir en sociedad y en armonía, a través de reglas claras y precisas que permitan racionalmente el respeto de lo nuestro, lo mío y lo tuyo, y en especial de la dignidad humana".
\end{abstract}

Rafael Sánchez Vázquez ${ }^{2}$

\section{RESUMEN}

¿Son los Principios Generales del Derecho (PGD) o Principios del Derecho, fuente del derecho? ¿Qué son y cuáles son sus funciones?, existe jerarquía entre ellas o respecto de la otras fuentes, estas son algunas de las interrogantes que se tratará de contestar en este artículo.

\section{PALABRAS CLAVES}

Principios Generales del Derecho. Fuentes del Derecho. Teoría Tridimensional. Características y Clasificación de Principio. Integración. Interpretación.

\section{ABSTRACT}

Are the General Principles of Law or Principles of Law sources of law? What are their functions? Is there any prevalence of such principles compared to the other sources? These are the questions this article intends to answer.

\section{Key Words}

General Principles of Law. Sources of Law. Three-dimensional Theory. Features and Classification of the Principle. Integration. Interpretation.

\section{DEFINICIÓN}

Principio, según el Diccionario de la Real Academia Española está definido como: base, razón fundamental sobre la cual se procede discurriendo en cualquier materia.

Existen diversidad de principios, no solo jurídicos, todas las ciencias tienen sus principios; $\mathrm{Mi}$ guel Reale ${ }^{3}$ señala: "Toda for- ma de conocimiento filosófico y científico implica la existencia de principios, es decir, de ciertos enunciados lógicos que se admiten como condición o base de validez de las demás afirmaciones que constituyen un determinado campo del saber".

Cuando hablamos de Principios Generales del Derecho (en adelante PGD) se hace refe- rencia a proposiciones abstractas y universales que dan razón, sustentan o fundamentan al sistema jurídico. También se les define como las ideas cardinales del Derecho que constituyen su origen o fundamento y que están dotadas de un alto grado de generalidad.

La página web wikipediawww.wikipedia.org -los define como: "los principios más

\footnotetext{
Abogado graduado en la PUC., profesor de la UNIFE. Ha dictado cátedra también en la Universidad de Lima y la USIL. Maestro, Doctor en Derecho por la UNAM, miembro del Sistema Nacional de Investigadores nivel III, de la Facultad de derecho y ciencia sociales de la Benemérita Universidad Autónoma de Puebla.
}

2 Introducción al Derecho. Ed.Pirámide Pag.139. 
generales de ética social, derecho natural o axiología jurídica, descubiertos por la razón humana, fundados en la naturaleza racional y libre del hombre, los cuales constituyen el fundamento de todo sistema jurídico posible o actual".

\section{Naturaleza - La teoría TRIDIMENSIONAL DEL DERECHO}

Respecto a los PGD se ha cuestionado si forman parte del derecho positivo o son externos a él. Para los iusnaturalistas se asimilan a los principios del derecho natural, serían por ende un conjunto de verdades universales, anteriores y externas al orden legal, más o menos inmutables, válidas en todo tiempo y espacio que constituyen el sustento de la legislación. Habría casos en que los principios adoptan expresamente la estructura jurídica de normas; por ejemplo cuando el principio es incorporado a la disposición o texto normativo.

Por otro lado se ha sostenido que los principios son una clase de norma. En cuanto a esta postura se precisa que los PGD no son sino normas fundamentales o generalísimas del sistema, las normas más generales.

Dos son los argumentos para sostener que los principios genera- les son normas de acuerdo con el primero de ellos, son normas aquellas que se deducen de los principios generales por medio de un procedimiento de generalización sucesiva. En segundo lugar la función para la cual se deducen y se adoptan es la misma que se lleva a cabo para todas las normas, o sea, la función de regular un caso.

La concepción positivista sostiene también que estos principios informan el derecho positivo, le sirven de fundamento pero una vez positivados pierden la naturaleza de principios y se convierten en norma. Esta posición ha sido adoptada también por los tribunales nacionales ${ }^{4}$. (Ver jurisprudencia al final de este artículo Henningsen versus Bloomfield Motors, Inc).

Una tercera posición sería la que plantea a los principios como una creación social real, producto de la conciencia de cada pueblo, que se adecua a este y a su evolución, son creados por lo tanto por el comportamiento social y están afincados en la conciencia común o en el espíritu del pueblo.

Como consecuencia de lo anterior, las medidas adoptadas por las autoridades, muchas de ellas contenidas en la legislación, han de consultar la realidad sobre la cual habrán de surtir efectos, con la finalidad de cumplir la función esencial del Estado y las instituciones públicas: promover mejores condiciones de vida a la población. Ello se aprecia, especialmente en las leyes en materia tributaria, las que establecen en principio un deber de los ciudadanos de contribuir al financiamiento de los gastos e inversiones del Estado dentro de principios de justicia y equidad.

Para Miguel Reale ${ }^{5}$ los PGD constituyen las bases teóricas y las razones lógicas del ordenamiento jurídico que recibe de ellas su sentido ético, su medida racional y su fuerza vital o histórica. De lo anterior se desprende que los principios generales del derecho no deben ser vistos en forma aislada de la problemática económica, social, cultural e ideológica de las sociedades humanas que se desenvuelven en un espacio y tiempo histórico concreto. José María Díaz Couselo ${ }^{6}$ refiriéndose a los PGD señala que ocupan un lugar peculiar entre las fuentes, porque valen antes que la Ley, en la Ley y después de la Ley, parecen situados en tres planos, el iusnaturalista anterior a la creación legislativa, el político o sea dentro de esta última y el científico-técnico, en la elaboración doctrinaria, jurisdiccional.

4 (2) El Tribunal Constitucional ha precisado:

Donde la oposición entre leyes anteriores y los principios generales plasmados en la Constitución sean irreductibles, tales principios, en cuanto forman parte de la Constitución, participan de la fuerza derogatoria de la misma, como no puede ser de otro modo. S. Pleno. TC 24/04/2006, Exp. 047-2004-AI/TC.

Los principios generales, en relación a las normas y los valores, han adquirido gran importancia para la interpretación jurídica, además de su indispensable aplicación para fines de integración jurídica. En ese contexto, un sector importante de la doctrina considera que los principios generales también pueden ser considerados como normas, aun cuando en algunos casos los principios no sean expresos. Hay casos en que los principios adoptan expresamente la estructura jurídica de normas; por ejemplo cuando el principio es incorporado a la disposición o texto normativo. En esta línea se ha sostenido que los principios son una clase de norma.

5 Obra Citada Pag.149.

6 Los Principios Generales del Derecho, Ed. Plus Ultra 1971, Pag. 583. 
Además de estas teorías tenemos las llamadas eclécticas que combinan una o más posiciones, sobre todo aquellas que dan a los PGD carácter positivo, al estar incorporado a la legislación y además carácter informativo ya que son sustento moral de todas las normas positivas.

Siguiendo la teoría tridimensional del derecho, el mundo jurídico estaría integrado por tres dimensiones: hecho, valor y norma ya que todo fenómeno jurídico se reduce a un hecho ordenado normativamente, según determinados valores.

El Dr. Carlos Fernández Sessarego señala acertadamente que estos tres elementos se integran en forma dialéctica, por lo que siguiendo esta teoría, en mi criterio, sería un error tratar de entender a los PGD solo desde un punto de vista unidimensional; los principios son un conjunto de valores que influyen en la ley (dimensión valorativa), algunos ya se encuentran expresamente incluidos en ella y otros en forma indirecta formando parte en todas las leyes (dimensión jurídica), no sin considerar que estos principios tienen una base real como conciencia social obligatoria formada en un tiempo y espacio dado (dimensión social).

\section{LOS PRINCIPIOS GENERALES COMO FUENTE DEL DERECHO}

La doctrina local tiene diversas posiciones respecto del valor como fuente de los PGD; la mayoría no los incluye dentro de la relación de fuentes formales considerándolos un medio de argumentación jurídica o técnica $y / o$ técnica de integración.

Marcial Rubio Correa7 expresa:

"Sin embargo, la teoría de las fuentes del derecho, considera que en un sistema determinado existen más fuentes que la legislación: están la jurisprudencia (vinculante o no vinculante), la costumbre, la doctrina y aún en ciertos casos la declaración de voluntad sobre lo cual existen, es cierto, discrepancias teóricas que no corresponde discutir aquí".

8 "Desde el punto de vista legislativo, en nuestro sistema jurídico no existen referencias a estas otras fuentes. Algunas excepciones son el ámbito tributario, el laboral y el agrario" "En su globalidad, el tema de los principios generales del derecho presenta varias dificultades, en especial dentro de sistemas pertenecientes a la familia romano-germánica, en los que la primacía de la fuente legislativa parece no dar lugar a conceptos de una naturaleza distinta que las normas aprobadas expresamente por los organismos de Estado de acuerdo a la teoría de las Fuentes".

Es interesante señalar que la Comisión Reformadora del Código Civil peruano vigente ha tenido una doble posición al redactar su Título Preliminar. En un primer momento se consideró a los PGD, de acuerdo al Art. $1^{\circ}$, como fuente junto a la Ley, La Costumbre y la Jurisprudencia, considerándola luego como un tipo de argumentación jurídica como también lo serían la analogía y la doctrina, de conformidad con el Art. $2^{\circ}$.

Dentro de los que le dan la característica de fuente, hay quienes le otorgan la característica de verdadera fuente del derecho pero otras la catalogan de fuente secundaria respecto de la ley.

En mi criterio la asimilación de los principios generales del derecho a la categoría de fuente dependerá del concepto que tengamos de fuente del derecho. Para quienes sostienen que para ser fuente formal es requisito que sea emitida por un poder del Estado con fuerza obligatoria; evidentemente, los PGD no podrían adquirir la categoría de fuente. Sin embargo el concepto de fuente del derecho ha evolucionado.

Enrique Aftalión, José Vilanova y Julio Raffo ${ }^{9}$ definen a las fuentes del derecho como: "la forma de determinación de normas generales (cómo determinarlas, cómo fundamentar esa determinación, a dónde nos dirigimos para encontrarlas), para fundamentar en ella los fallos o en general, para asignarle sentido jurídico a los casos individuales".

"Fuentes serían lo que es invocado como derecho aplicable ya sea por el juez al aplicar una sentencia, ya sea por las partes en su intento de con- 
vencer al juez de cómo ser la sentencia que debe dictarla, fuentes aparecen así en las sentencias cuando llega el momento de decidir cuál es el derecho a aplicar o bien se aplica la ley, y/o una costumbre $\mathrm{y} / \mathrm{o}$ aplica una jurisprudencia $\mathrm{y} / \mathrm{o}$ aplica la doctrina."

En sentido similar se pronuncia Julio AntoRua ${ }^{10}$ cuando precisa que las fuentes son útiles como fuentes por cuanto suministran un criterio material para discernir el sentido del caso en discusión de una manera considerada valiosa.

Isidora Martín catedrática de la Universidad de Madrid España también aboga por la ambigüedad del término y necesidad de aclarar la terminología señalando que la expresión "fuentes del derecho" alude a los conceptos de donde surge el contenido del derecho vigente en un espacio y momento dado; son los "espacios" a los cuales se debe acudir para establecer el derecho aplicable a una situación jurídica concreta.

Coincido con esta nueva concepción de fuente, más allá de las fuentes materiales y formales, por la que los principios generales por ser de uso y recurso permanente de legisladores, jueces y abogados serían fuente del derecho. En este sentido como ya se ha precisado son una fuente del derecho muy importante y fuente de fuentes.

\section{Características}

Se puede enumerar como las principales características de los PGD a las siguientes: a) Contenido axiológico. Ya que siempre deben tener contenido ético y de valor; un principio sin contenido ético no es principio. Los principios siempre encarnan determinados deberes o derechos.

b) Generalidad y ausencia de concreción. En vista que se formulan mediante expresiones no escritas, como no ocurre con la ley. Nada impide que un principio se recoja por el legislador, pero no es ésta la tónica general, quizá porque la utilidad de los principios deriva de su generalidad existiendo más allá de la Ley.

c) Supletoriedad ante la ley. Tienen independencia respecto de las normas concretas positivas lo que hace que informen al ordenamiento sin necesidad de que sean materializados. Habría que tener en cuenta que cuando un principio general del derecho se convierte en ley, ya no es principio general del derecho sino ley y como fuente del derecho debe ser conjugada por el Juez en primer lugar, no en régimen de subsidiariedad.

d) Universalidad. - Ya que opera en diversos espacios y tiempos y su validez es común a todos los pueblos. Dos pueden ser los fundamentos de su alcance universal, el primero es que existen principios que podríamos calificar de congénitos a la naturaleza humana, o que también son conocidos como principios de derecho natural; y el otro de los fundamentos son una serie de principios formados por disposiciones legales expresas o resultantes de la unidad de la legislación nacional. e) Fundamentalidad.- Son el nexo integrador del derecho. Así, ningún ordenamiento legal sería posible sin un conjunto de principios generales capaces de armonizar e integrar el conjunto de normas permanentes y caóticas que coexisten en la legislación, hasta convertirla en un sistema operante y fluido.

\section{Clasificación}

Los PGD han sido clasificados por diferentes juristas, y por ende, su sistematización es diferente, según la corriente doctrinal de cada cual. Así se puede distinguir algunas clasificaciones:

a) Del derecho natural, principios tradicionales y principios políticos.

b) De apreciación e interpretación para todo género de relaciones jurídicas.

c) Del derecho civil, penal, administrativo, laboral etc.

d) De carácter universal y principios propios de cada Estado o sistema jurídico. Los segundos o principios propios de cada estado o sistema jurídico, se clasifican, en principios constitucionales y principios generales propios de cada rama del ordenamiento jurídico

e) Inmediatos y mediatos. Los primeros que expresan los valores de toda sociedad y los segundos ya se encuentran incorporados en las normas en cada sistema en específico.

f) Omnivalentes, válidos en todas las formas del saber (principio de la identidad); Plurivalen-

10 Introducción al Derecho Ed. Abelardo Perrot, Buenos Aires 1982 , pag.27. 
tes válidos en varias áreas del conocimiento) y monovalentes como sería el caso de los PGD.

g) Principios positivos particulares; jurídicos positivos sistemáticos, teleológicos o metapositivos y doctrinarios o filosóficos políticos, de acuerdo con Eugenio M. Ramirez Cruz. ${ }^{11}$

h) En el Perú nuestra Constitución los clasifica en generales y consuetudinarios y el Código Civil en Generales y aquellos que inspiran la legislación peruana, aunque el autor ha leído en algún texto que resultaría una contradicción del lenguaje tratar de entender que existen principios generales del derecho, por ejemplo peruanos, ya que la palabra general es para todos, alude más a su carácter universal.

\section{LAS FUNCIONES DE LOS PGD}

Los principios generales del derecho se dice, han cumplido diversas funciones:

\section{Función de Información e Ins- piración}

Porque orientan y sirven de base en la elaboración de las demás fuentes, llámese principalmente la legislación, pero también la doctrina, la jurisprudencia y hasta la fuente negocial también llamada declaración de voluntad.

Los PGD son el sustento de todo orden jurídico, como fuente material de la cual se crearon todas las normas legales, para unos es una fuente de fuentes, otorgándosele la función creadora del derecho por excelencia ya que fija los criterios que se deberá tener para la elaboración, modificación o derogación de las normas.

La labor informativa o de inspiración se aprecia claramente en la legislación pero también en la doctrina y jurisprudencia, los PGD se emplean como instrumentos invocados reiteradamente por los tribunales, por ejemplo como freno al poder legislativo.

Los principios generales se ha dicho, son los que convierten esa masa en forma de leyes y jurisprudencia en Derecho. La coherencia de cualquier rama del Derecho y del Derecho mismo en su conjunto solo es posible gracias a un repertorio de principios; son por tanto éstos, los que le dan vida al Derecho.

\section{Función de Interpretación}

Porque permite saber cómo, aplicando una norma general a un hecho concreto, el Intérprete obtiene la norma individual que le incumbe establecer; por ejemplo el de interpretar de acuerdo a la buena fe, la sistemática de un correcto entendimiento de las normas o del orden jurídico; las leyes, si han de estar informadas por aquellos principios, han de ser interpretadas en el momento de su aplicación de acuerdo a los principios que las inspiraron. Por ello en la actualidad, la función interpretativa que realiza el jurista o el juez no debe únicamente limitarse a la aplicación de la ley previamente establecida en la legislación, sino que la interpretación de las leyes, debe ser un estudio profundo de los prin- cipios generales del derecho, porque son ellos los que en última instancia se toman en cuenta para resolver todas las cuestiones en las cuales el texto de la ley es oscuro, contradictorio e insuficiente, para solucionar la situación jurídica controvertida. Acude el juez, legislador, abogado y ciudadano común a los principios para dar solución.

Es necesario que exista un mecanismo que permita al juez adecuar la norma a la situación jurídica concreta en un asunto determinado con sujeción a determinados principios que permitan darle seguridad jurídica al ciudadano, es decir, permitir al juez que al aplicar una determinada disposición, ésta pueda ser flexible a fin de utilizarla en el caso concreto que se plantea hasta donde permitan los principios generales del derecho que se encuentran previamente establecidos y, al realizar esta función se construya el derecho.

Por todo lo anterior, se puede concluir que los PGD constituyen un factor determinante en la interpretación jurídica, pues la presencia de éstos, en forma consciente o inconsciente en tal labor, va a ser la condensación de lo que un sistema ha consagrado como la finalidad del derecho y que, a la vez, es su punto de partida y su base interpretativa. Dicho de otra manera, los PGD son la savia que nutre el árbol frondoso del derecho. Son enunciados de naturaleza normativa aceptados universalmente o regionalmente que sirven de sustento al derecho positivo y que sirven para la interpretación del derecho y

11 Fuentes del Derecho Civil Peruano, Editorial Rohdas, 2003, pags.224 a 225. 
la aplicación de los jueces. Son fuente de las normas jurídicas particulares de las cuales el legislador se nutre.

Función Integradora o subsidiaria

Permite suplir o colmar las lagunas de la ley creando o constituyendo un derecho.

Para colmar una laguna legal es necesario integrar el Derecho ya existente según los principios; por último, las lagunas legales en el derecho positivo no existen debido a la posibilidad que tienen los miembros judiciales para interpretar una norma ya creada y adaptarla según los principios generales, lo que garantiza una seguridad jurídica sólida frente a la positivización del Derecho. Estos principios son utilizados por los jueces, los legisladores, los creadores de doctrina y por los juristas en general, sea para integrar lagunas legales o para interpretar normas jurídicas cuya aplicación resulta dudosa.

De este modo, el Derecho solo puede crearse, recrearse, explicarse y aplicarse a través de los principios generales. Así, todo el Derecho está impregnado de principios hasta en sus más simples problemas. En suma, no es posible pensar en un Derecho sin principios.

Esta función integradora ha sido reconocida en la Constitución Peruana de 1993 al señalar en su Art.139,Inc.8: Son principios de la función jurisdiccional: El principio de no dejar de administrar justicia por vacío o deficiencia de la ley.
En tal caso, deben aplicarse los principios generales del derecho y el derecho consuetudinario.

Similar situación se encuentra en el Artículo VIII del Título Preliminar de nuestro Código Civil que indica: Los jueces no pueden dejar de administrar justicia por defecto o deficiencia de la ley. En tales casos, deben aplicar los principios generales del derecho y preferentemente los que inspiran el derecho peruano.

\section{Función Limitativa}

Por último, sólo me cabe resaltar que los principios generales del derecho además, cumplen la función limitativa cuando éstos demarcan ordenadamente relaciones entre normas jurídicas de jerarquía superior con otras de rango menor.

\section{JERARQUía DE O ENTRE PRINCIPIOS}

No existe una posición unánime en la doctrina sobre la jerarquía de los principios respecto de las demás fuentes del derecho, más aun si tenemos en cuenta que algunos le desconocen la característica de fuente, como ya se comentó.

Han sido múltiples los intentos por graficar o diseñar una teoría de las jerarquías de las fuentes del derecho inclusive en el Perú. No se puede negar la utilidad práctica de tener una jerarquía de fuentes claras y precisas, lamentablemente el tema de la jerarquías parece que hay que analizarlo dependiendo de la especialidad del derecho, inclusive caso por caso.
Si bien en la mayoría de situaciones se exige la primacía de la Ley, no es menos cierto que la declaración de voluntad o la costumbre pueden primar sobre ésta, dentro de las limitaciones que se conocen como el orden público y las buenas costumbres o las prescripciones de la misma Ley. Inclusive los principios se pueden encontrar a la par de la ley o la jurisprudencia o inclusive por encima de ella como en el largamente comentado caso de los procesos de Nuremberg.

Joaquín Arce y Flórez-Valdez ${ }^{12}$, precisan: "Los principios generales son ahora una fuente supletoria , desde luego; pero principalmente, una fuente material básica y primaria de nuestro ordenamiento jurídico, capaz, de adquirir primacía en un puro orden jerárquico, sobre la ley y la costumbre, con virtualidad para matizarlas, con fuerza para generarlas, con potencialidad para invadirlas. Son, en definitiva una super fuente por cuanto pueden ser fuente de las mismas fuentes".

Tomando en consideración la pirámide de Kelsen, los PGD se encontrarían en su parte más baja, en su base, ya que gráficamente serían el soporte e inspiración de todas las demás normas jurídicas y a su vez son utilizados cuando las demás fuentes formales del derecho no dan una respuesta a un problema particular y que se plantea en una situación determinada.

Por tanto algunos establecen una prelación de fuentes dán-

12 Los principios Generales del Derecho y su Formulación Constitucional. Ed.Civitas 1990. 
dole a los PGD, la posibilidad de ser utilizados sólo cuando la legislación y las demás fuentes reconocidas en el ordenamiento no han sido capaces de dar solución a un determinado asunto en particular.

En el Perú, dice Eugenio Ramirez Cruz ${ }^{13}$ :" No queda duda pues en cuanto a su reconocimiento en el orden jurídico positivo. Más bien habría que establecer cierto orden o jerarquía en cuanto a las fuentes supletorias del derecho. Según la tradición racionalista, es la ley la que ocupa el primer lugar entre ellas; el problema o contradicción se presenta en las demás. Pero ella es más bien aparente. Si aplicáramos el artículo VII, el orden sería la Ley, costumbre, jurisprudencia y doctrina, mientras que, si aplicáramos los artículos IV y VIII, en defecto de la ley no habría que recurrir directamente a la costumbre sino a los principios del derecho peruano, los principios generales del derecho y a la analogía".

Por otro lado, se pregunta la doctrina si existen principios jerarquizados es decir si algunos prevalecen sobre otros. Al respecto parece la doctrina considerar que existen principios de principios como la vida y la libertad que se sobreponen a otros y, en caso de conflicto, debe preferirse los primeros. Estos conflictos principistas se aprecian frecuentemente en los tribunales, recientemente por ejemplo se está presentando el debate sobre el matrimonio o unión entre personas del mismo sexo en donde entrarían en conflicto los principios de la libertad, no discriminación y autonomía de la voluntad versus el principio de la protección de la familia y el bien común o, como en el caso del aborto, en donde se enfrenta el derecho a la vida con el derecho a la libertad.

Es evidente que esta jerarquización sí existe y cada sistema ha ido creando, ya sea por la voluntad popular, costumbres, religión, jurisprudencia o por cualquier otro medio, esta jerarquía sobre la que se basa su estructura moral en donde definitivamente, reitero, existen principios irrenunciables y fundamentales que priman sobre otros.

\section{LOS PRINCIPIOS EN LA LEGISLACIÓN COMPARADA}

El artículo 38.1.c) del Estatuto de la Corte Internacional de Justicia considera a los principios generales del Derecho una fuente formal del derecho internacional, al lado de la costumbre internacional y los tratados internacionales, por lo cual el tribunal estaría obligado a aplicarlos sin necesidad de que exista una laguna en cuanto al alcance de estas dos últimas fuentes; es decir, opera como fuente autónoma y no subsidiaria.

\section{Argentina}

El Código Civil , consagra en su artículo 16, el siguiente enunciado: "Si una cuestión civil no puede resolverse, ni por las palabras, ni por el espíritu de la ley, se atenderá a los principios de leyes análogas; y si aún la cuestión fuere dudosa, se resolverá por los principios generales del derecho, teniendo en consideración las circunstancias del caso".

\section{Colombia}

La Constitución Política Colombiana de 1991, en su artículo 230 , precisa que los principios generales del derecho son criterios auxiliares en caso de insuficiencia de la Ley, es decir, en caso de obscuridad o vacíos normativos.

\section{España}

Según el artículo 1.1 del Código Civil, las fuentes del ordenamiento jurídico son «la ley, la costumbre y los principios generales del Derecho. $Y$ en su artículo 1.4 sigue: Los principios generales del derecho se aplicarán en defecto de Ley o costumbre, sin perjuicio de su carácter informador del ordenamiento jurídico.

\section{México}

En el derecho mexicano, el artículo 14 de la Constitución política vigente señala que los juicios de orden civil deberán fallarse conforme a la letra o a la interpretación de la Ley, y a falta de ésta, se fundará en los principios generales del Derecho.

\section{Brasil}

El código civil da fuerza integradora a los principios conforme se aprobara mediante

13 Obra citada, pag. 226. 
D.Lei 4,657 de setiembre de 1942, Art 4.

\section{Uruguay}

Código Civil Art. 16. Cuando ocurra un negocio civil, que no pueda resolverse por las palabras ni por el espíritu de la ley de la materia, se acudirá a los fundamentos de las leyes análogas; y si todavía subsistiere la duda, se recurrirá a los principios generales del derecho y a las doctrinas más recibidas, consideradas las circunstancias del caso.

\section{Venezuela}

Código Civil, Artículo 4. A la Ley debe atribuírsele el sentido que aparece evidente del significado propio de las palabras, según la conexión de ellas entre sí y la intención del legislador. Cuando no hubiere disposición precisa de la Ley, se tendrán en consideración las disposiciones que regulan casos semejantes o materias análogas; $y$, si hubiere todavía dudas, se aplicarán los principios generales del derecho.

\section{CASO HENNINGSEN VS BLOOM- FIELD.}

En 1960, un tribunal de Nueva Yersey se enfrentó, en el Henningsen vs. Bloomfield Motors, Inc., con la importante cuestión de si un fabricante de automóviles puede y en qué medida limitar su responsabilidad en el caso que el automóvil sea defectuoso. Henningsen había comprado un automóvil, y firmado un contrato que decía que la responsabilidad del fabricante por defectos se limitaba a "reparar" las partes defectuosas "quedando esta garantía expresa en lugar de todas las demás garantías, obligaciones o responsabilidades".
Henningsen argüía que, al menos en las circunstancias de su caso, el fabricante no debía de ser protegido por esta limitación y que debería de responder por los gastos médicos y otros hechos por las personas lesionadas en el accidente. El demandante no pudo señalar ninguna ley, ni ninguna regla de derecho establecida que impidiera que el fabricante se sustentara en los términos del contrato. No obstante, el tribunal estuvo de acuerdo con Hennigsen. En diversos puntos de la argumentación del tribunal se hicieron las siguientes referencias a principios:

a). "Nosotros debemos recordar el principio general de que en ausencia de fraude, quien no desea leer el contrato antes de firmarlo no puede luego librarse de sus cargas";

b). "Al aplicar dicho principio, la tesis básica de la libertad de contratación es un factor de importancia";

c). "Libertad de contratación no es una doctrina de tal modo inmutable como para admitir específicamente en el área que nos concierne";

d). "En una sociedad como la nuestra, en la que el automóvil es un implemento común y necesario de la vida diaria, y en la que su uso está tan cargado de peligros para el conductor, los pasajeros y el público, el fabricante está bajo una especial obligación con respecto a la construcción, promoción y venta de sus automóviles. En consecuencia, los tribunales deben examinar cuidadosamente los contratos de compraventa para ver si los inte- reses del consumidor y del público son equitativamente considerados";

e). "¿Acaso existe algún principio que sea más familiar o que esté más firmemente inmerso en la historia del derecho angloamericano que la doctrina básica de que los tribunales no deben permitir el ser usados como instrumentos de iniquidad e injusticia?" y;

f). "Más específicamente, los tribunales generalmente se niegan a prestarse para la imposición de un arreglo en el cual una de las partes ha tomado ventaja injustamente de las necesidades económicas de la otra".

Habida cuenta, nos percatamos que los principios juegan un papel relevante a fin de resolver los problemas jurídicos, cuando falta un precepto satisfactorio, dicho de otra manera, como contenedores potenciales de cualquier solución justa en el orden de ideas básicas o fundantes de un determinado sistema.

De ahí, que para Dworkin, no es válida la argumentación de los positivistas acerca de que los principios no pueden contar como derecho porque su autoridad,y más aún su peso, es congénitamente polémico. Toda vez, que al asociar lo antes citado con un contra - argumento que se opone a la doctrina positivista, ya que, si no se reconoce que algunos principios son obligatorios para los jueces, exigiéndoles en conjunto que lleguen a determinadas decisiones, entonces tampoco de ninguna o de muy pocas reglas puede decirse que son obligatorias para ellos. 